\title{
Influência da composição das matérias-primas no processo de gresificação de revestimentos cerâmicos
}

\author{
(Influence of raw materials composition on the \\ vitrification process of ceramic tiles)
}

\author{
L. Sánchez-Muñoz ${ }^{1}$, S. da S. Cava ${ }^{2}$, C. A. Paskocimas ${ }^{2}$, \\ E. Cerisuelo ${ }^{3}$, E. Longo ${ }^{2}$, J. B. Carda ${ }^{1}$ \\ ${ }^{1}$ Dpto. Química Inorgánica y Orgánica, Universidad Jaume I, Castellón, Espanha \\ ${ }^{2}$ Centro Multidisciplinar de Desenvolvimento de Materiais Cerâmicos, S. Carlos, SP, Brasil \\ ${ }^{3}$ Tierra Atomizada, S.A., Alcora, Castellón, Espanha
}

\begin{abstract}
Resumo
A partir do uso de matérias-primas convencionais e não convencionais, foram formuladas diversas séries de massas cerâmicas para revestimentos gresificados (isto é, sem carbonato), obtendo seus diagramas de gresificação (absorção de água e retração linear em função da temperatura). As alterações mineralógicas e microestruturais das massas devidas ao processo de queima foram acompanhadas por Microscopia Eletrônica de Varredura. Os resultados mostram que a partir de diferentes tipos de matérias-primas, não só é possível obter massas cerâmicas de grés porcelânico, como também a diminuição da temperatura máxima de queima, mantendo a estabilidade dimensional.
\end{abstract}

Palavras-chave: gresificação, massas cerâmicas, revestimentos cerâmicos.

\begin{abstract}
Starting from the use of conventional and non-conventional raw materials, several series of ceramic bodies were formulated for vitrified ceramic tiles (that is, without carbonate), obtaining vitrification curves (water absorption and linear shrinkage as a function of temperature). The mineralogical and microstructural alterations due to the firing process were accompanied by Scanning Electron Microscopy. The results show that starting from different types of raw materials, not only it is possible to obtain ceramic bodies for porcelain tiles, but also the decrease of the maximum firing temperature, maintaining the dimensional stability.
\end{abstract}

Keywords: vitrification, ceramic bodies, ceramic tiles.

\section{INTRODUÇÃO}

As massas para grés são elaboradas com altos conteúdos em argilas (normalmente misturas de argilas fundentes e argilas refratárias) e baixos conteúdos em feldspatos [1]. A presença de quartzo na massa é proveniente das diferentes matériasprimas, e também pode ser adicionado como material nãoplástico. A queima é realizada em fornos a rolos convencionais, com temperaturas máximas ao redor de $1150{ }^{\circ} \mathrm{C}$ em ciclos de cerca de 35-45 minutos [2], resultando em materiais cerâmicos formados por mulita (formada a partir da caulinita das argilas), quartzo (que atua como inerte), feldspatos residuais e vidro (procedente da fusão e posterior vitrificação de parte do componente argiloso e de parte de feldspatos) [3]. Devido a sua porosidade, o grés não deve ser empregado em exteriores em regiões de clima frio, já que apresenta deficiência na resistência ao congelamento.

A porosidade é um resultado indesejável do processo de gresificação das massas cerâmicas que afetam negativamente as propriedades físicas e químicas dos materiais cerâmicos. Na Fig. 1 é apresentada uma micrografia obtida por MEV da seção transversal de uma peça de revestimento cerâmico gresificado que ilustra os três tipos fundamentais de porosidade: aberta, fechada e interparticular.

A porosidade aberta é formada por espaços irregulares intercomunicados, que em seção aparecem como poros irregulares, normalmente com tamanhos inferiores a $5 \mu \mathrm{m}$. Sua extensão é diretamente relacionada com a resistência ao congelamento, que é uma característica distinta entre os materiais de grés e grés porcelânico. Esta pode ser avaliada mediante medidas de absorção de água ou de porosimetria de mercúrio [4].

A porosidade fechada consiste em espaços de forma esférica cujo tamanho em seção é normalmente superior a $10 \mu \mathrm{m}$. Nos suportes polidos, a porosidade fechada está exposta na superfície, e sua abundância é responsável pela resistência às 


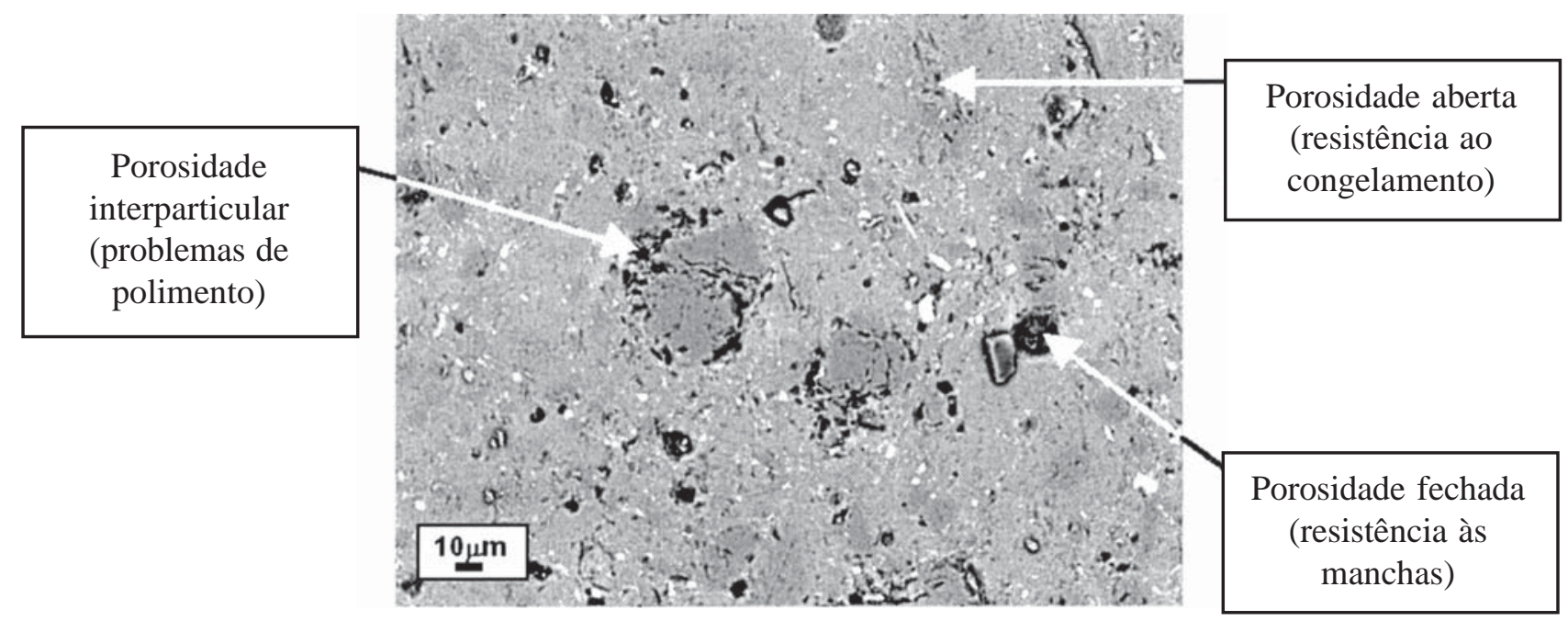

Figura 1: Aspecto dos três tipos de porosidade de revestimentos cerâmicos quando observa-se por MEV, empregando o detector de elétrons retroespalhados. As setas indicam as regiões representativas de porosidade aberta, fechada e interparticular.

[Figure 1: Aspect of the three types of porosity of ceramic tiles when observed by SEM using the detector of backscattered electrons. The arrows indicate the representative areas of open, closed and interparticle porosity.]

manchas, já que nestes buracos se alojam partículas sólidas de modo irreversível.

A porosidade interparticular tem aspecto irregular e se localiza nos contornos entre os grãos residuais e a matriz vítrea. Sua importância está não só em perda de resistência mecânica dos suportes, mas também em deficiências nas superfícies quando são polidas [5]. Isto é devido a esta porosidade, que causa deficiência na aderência dos grãos do material que separa a superfície com facilidade durante o processo de abrasão.
Consequentemente, também diminui a resistência às manchas.

Em função da porosidade aberta pode-se distinguir dois tipos de materiais cerâmicos de revestimentos: grés (com absorção de água superior a 0,5\% e menor que 50\%) e grés porcelânico (com este valor inferior para $0,5 \%$ ). As matériasprimas utilizadas nas respectivas formulações de massas são semelhantes, mas em proporções notadamente diferentes, e principalmente, diferentes ciclos de queima (Fig. 2).

Com o objetivo de diminuir a porosidade do produto

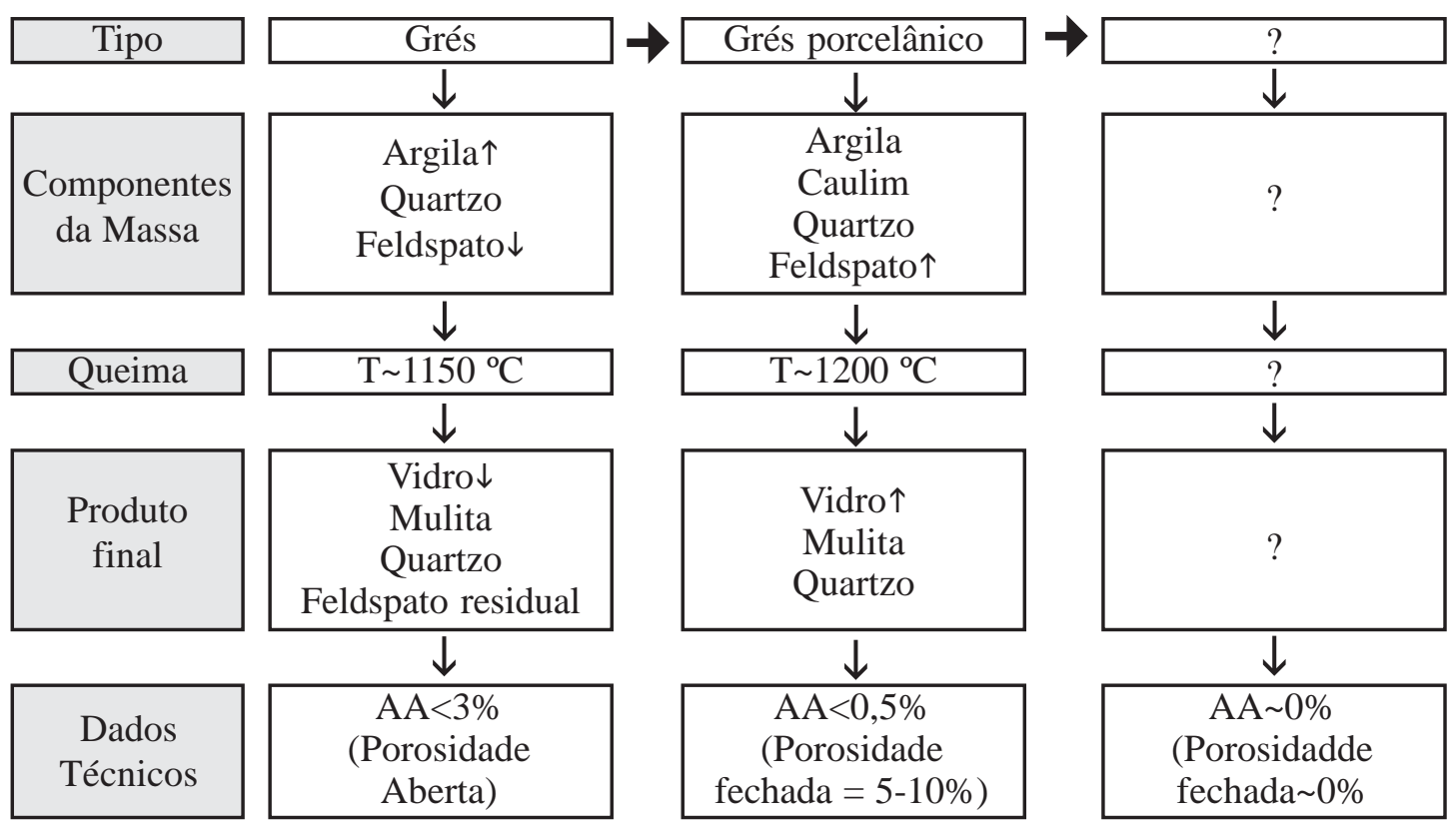

Figura 2: Esquema de dados tecnológicos para produtos gresificados.

[Figure 2: Outline of technological data for vitrified products.] 


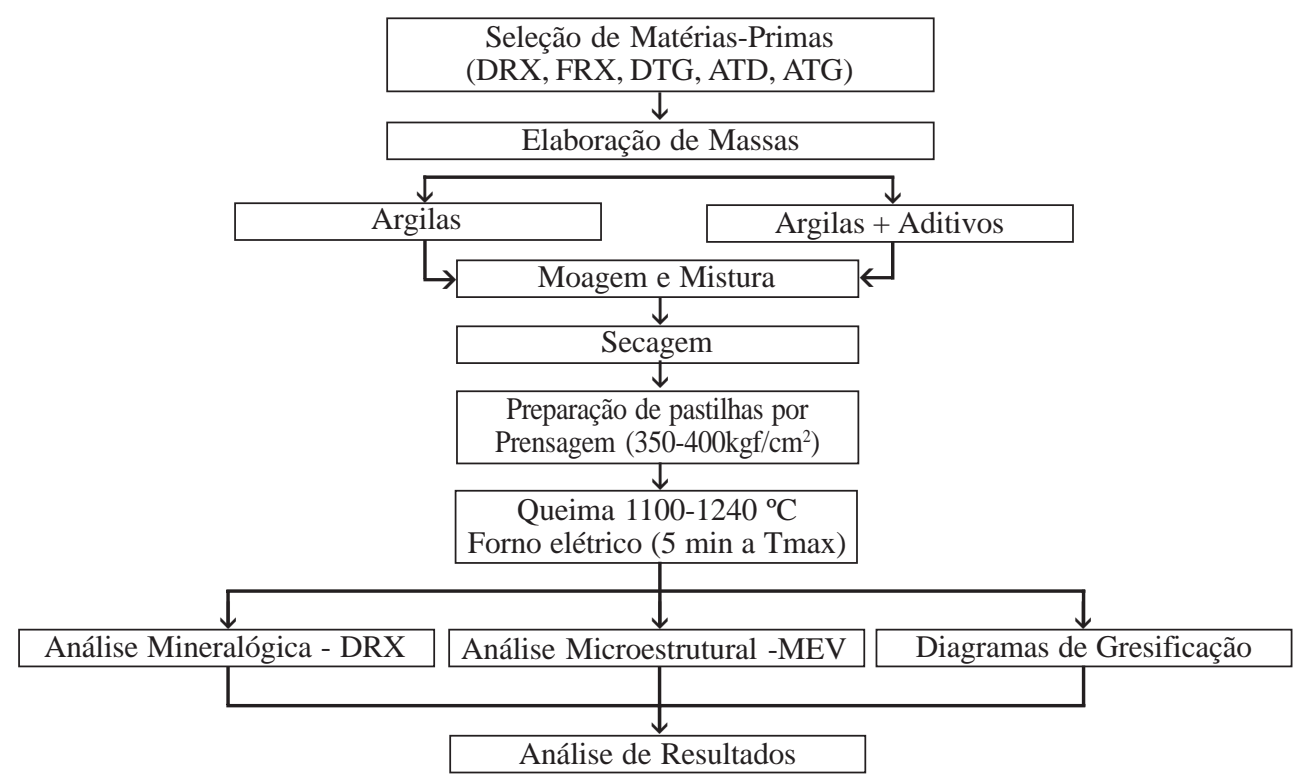

Figura 3: Esquema da metodologia de trabalho adotada. [Figure 3: Outline of the adopted methodology.]

acabado, a indústria cerâmica desenvolveu os revestimentos de grés porcelânico, cuja baixa porosidade aberta permite o uso em exteriores, além das conseqüentes melhorias nas propriedades de resistência mecânica. De forma simplificada, as massas para grés porcelânico são elaboradas com menores proporções de material argiloso, mas com um aumento considerável dos conteúdos em feldspatos e frequientemente com a incorporação de caulim [6]. O quartzo está presente nestas três matérias-primas, mas sua adição pode ser necessária para otimizar os valores de plasticidade. Com esta nova formulação, a baixa porosidade é obtida ao redor de $1200{ }^{\circ} \mathrm{C}$ em ciclos de queima de 45-60 minutos. Neste caso, ocorre a fusão total dos feldspatos, como na porcelana. Então, o grés porcelânico é formado por maiores conteúdos em mulita e em fase vítrea que o grés, ficando o quartzo sem reagir com o resto dos componentes. Ao contrário do grés, o grés porcelânico normalmente apresenta porosidade fechada, normalmente em porcentagens compreendidas entre $5 \%$ e $10 \%$.

Porém, a diferença fundamental entre estes materiais cerâmicos está nas características do forno de produção. Assim, para a produção do grés porcelânico, são usados fornos projetados para a queima deste material, sendo os refratários específicos para temperatura mais alta, assim como as dimensões, que são superiores. Por isso, o preço de um forno para grés porcelânico é sensivelmente maior ao do grés convencional. Como conseqüência, quando uma empresa

Tabela I - Análises químicas das diversas matérias-primas estudadas (M1 a M9).

[Table I - Chemical analysis of all studied raw materials (M1 to M9).]

\begin{tabular}{|c|c|c|c|c|c|c|c|c|c|c|c|}
\hline & & & $\mathrm{SiO}_{2}$ & $\mathrm{Al}_{2} \mathrm{O}_{3}$ & $\mathrm{TiO}_{2}$ & $\mathrm{Fe}_{2} \mathrm{O}_{3}$ & $\mathrm{CaO}$ & $\mathrm{MgO}$ & $\mathrm{Na}_{2} \mathrm{O}$ & $\mathrm{K}_{2} \mathrm{O}$ & PF \\
\hline Matérias-Primas & $\mathrm{AP}$ & M1 & 56,54 & 29,65 & 1,14 & 1,57 & 0,06 & 0,22 & 1,34 & 3,70 & 5,78 \\
\hline \multirow[t]{4}{*}{ Tradicionais } & $\mathrm{NP}$ & M2 & 90,82 & 5,24 & 0,09 & 0,11 & 0,05 & 0,02 & 0,04 & 2,63 & 1,00 \\
\hline & $\mathrm{F}$ & M3 & 67,96 & 18,12 & 0,02 & 0,10 & 0,30 & 0,30 & 4,03 & 8,56 & 0,60 \\
\hline & & M4 & 57,42 & 6,61 & 0,30 & 0,71 & 32,52 & 0,61 & 1,42 & 0,41 & 0,00 \\
\hline & $\mathrm{NP}+\mathrm{AP}$ & M5 & 82,08 & 11,98 & 0,03 & 0,62 & 0,09 & 0,27 & 0,00 & 3,09 & 1,84 \\
\hline \multirow{4}{*}{$\begin{array}{l}\text { Materiais } \\
\text { geológicos } \\
\text { especiais }\end{array}$} & $\overline{F+A P}$ & M6 & 73,62 & 10,15 & 0,16 & 0,87 & 0,17 & 5,05 & 0,03 & 6,95 & 3,00 \\
\hline & & M7 & 64,06 & 22,48 & 0,01 & 0,44 & 0,35 & 0,21 & 9,32 & 2,13 & 1,01 \\
\hline & & M8 & 50,70 & 31,86 & 0,24 & 1,55 & 0,48 & 0,67 & 0,05 & 0,76 & 13,70 \\
\hline & $\mathrm{C}+\mathrm{F}$ & M9 & 73,62 & 10,15 & 0,16 & 0,87 & 0,17 & 5,05 & 0,03 & 6,95 & 3,00 \\
\hline
\end{tabular}

$A P=$ Argila plástica $; N P=$ Material não-plástico $; F=$ Fundente $; C=$ Caulim. 
Tabela II - Análises mineralógicas das matérias-primas estudadas (M1 a M9).

[Table II - Mineralogical analysis of studied raw materials (M1 to M9).]

\begin{tabular}{llllllllll}
\hline & M1 & M2 & M3 & M4 & M5 & M6 & M7 & M8 & M9 \\
\cline { 2 - 9 } & 41 & 90 & 10 & 2 & 70 & 25 & - & 3 & 10 \\
\hline Caulinita & 13 & - & - & - & - & - & - & 75 & 35 \\
\hline Ilita & 46 & - & - & - & 30 & 25 & - & 7 & 35 \\
\hline Albita & - & 2 & 45 & - & - & 25 & 90 & - & 12 \\
\hline Ouscovita & - & - & - & - & - & - & 10 & - & - \\
\hline Wolastonita & - & - & - & 70 & - & - & - & - & - \\
\hline Plagioclásio & - & - & - & 20 & - & - & - & - & - \\
\hline Diópsido & - & - & - & 7 & - & - & - & - & - \\
\hline Calcita & - & - & - & 1 & - & - & - & - & - \\
\hline Montmorilonita & - & - & - & - & - & - & - & 15 & - \\
\hline
\end{tabular}

decide fabricar grés porcelânico tem que confrontar gastos substanciais em novas infra-estruturas. O passo seguinte na evolução das cerâmicas industriais para revestimentos (terceira coluna da Fig. 2) deveria incluir, não só a ausência de porosidade aberta, mas também diminuições importantes na porosidade fechada. Também, seria muito interessante se tais materiais pudessem ser fabricados com os fornos convencionais de produção de grés.

\section{PROCEDIMENTO EXPERIMENTAL}

A metodologia de trabalho usada neste trabalho é representada de forma esquemática na Fig. 3, indicando a seqüência lógica de atividades realizadas no desenvolvimento do mesmo como um fluxograma geral.

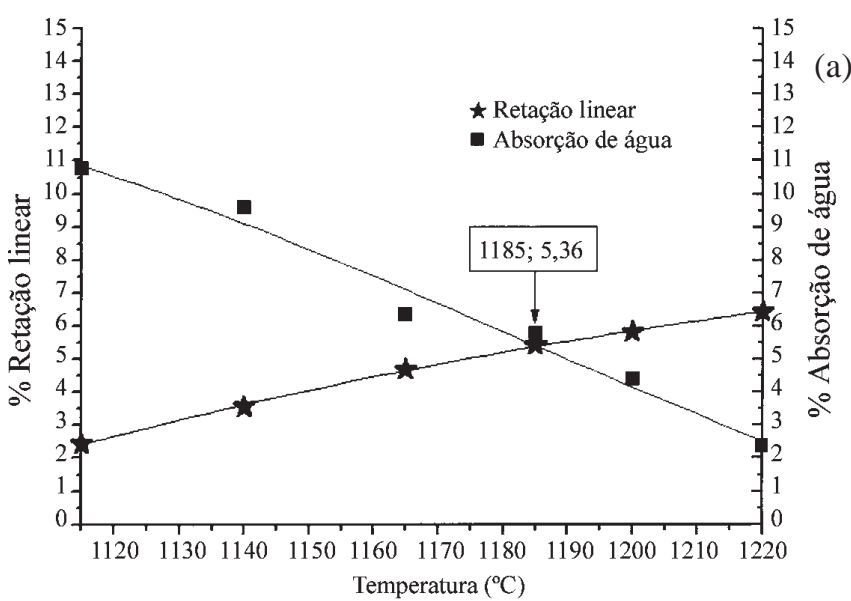

Para a elaboração de massas cerâmicas de queima branca, foram utilizadas 9 matérias-primas de dois tipos diferentes. Em primeiro lugar, foi feita uma seleção das matérias-primas convencionais representativas que são normalmente usadas na indústria de produção de revestimentos. Em segundo lugar, foram utilizadas matérias-primas não convencionais ou materiais geológicos especiais (rochas), todas elas de origem nacional. Também, utilizou-se os defloculantes habituais do processamento via úmida de massas (metassilicato de sódio e tripolifosfato de sódio). As respectivas análises químicas (obtidas por meio de fluorescência de raios X - FRX) e mineralógicas (obtidas por meio de difração de raios X - DRX) são apresentadas nas Tabelas I e II.

As matérias-primas tradicionais, de origem espanhola, são as seguintes:

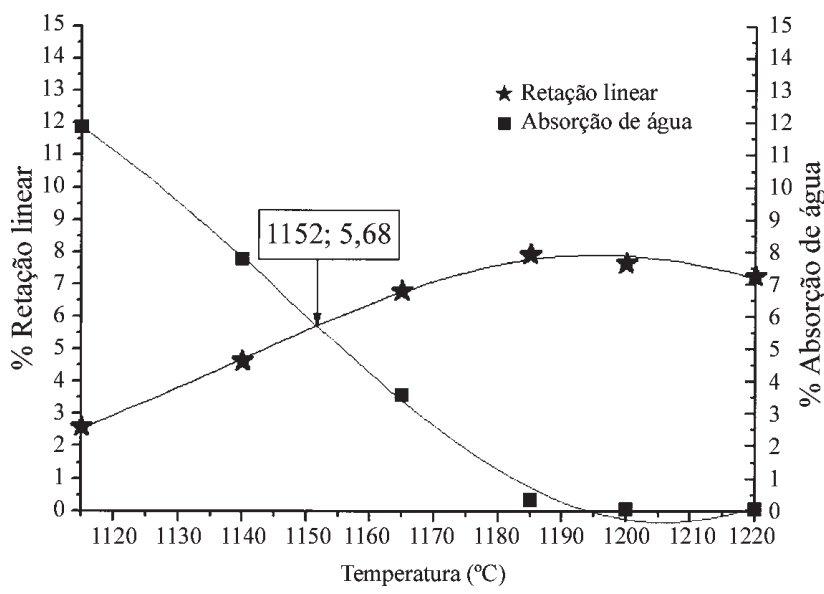

(b)

Figura 4: Curva de gresificação de composições de massas tradicionais (ver Tabela III). a) Massa 1a - Amostra de argila M1, b) Massa 1b $40 \%$ argila M1 + 20\% quartzo M2 + 20\% feldspato M3 (as composições mineralógicas de M1, M2 e M3 estão na Tabela II).

[Figure 4: Vitrification curves of traditional whitewares mixes (see Table III). a) mix 1a - clay sample M1, b) mix $1 b-40 \%$ clay M1 + 20\% quartz M2 + 20\% feldspar M3 (the mineralogical compositions of M1, M2 and M3 are in Table II).] 


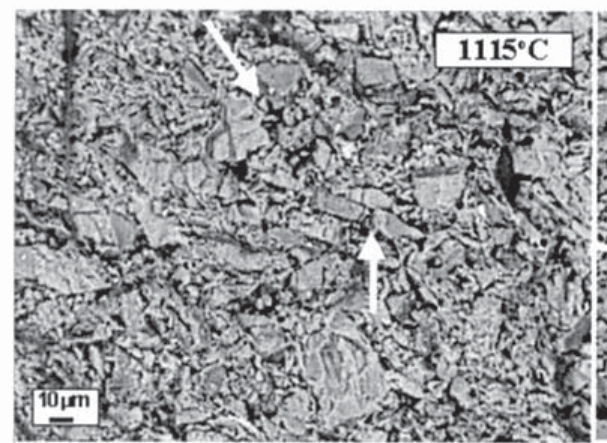

(a)

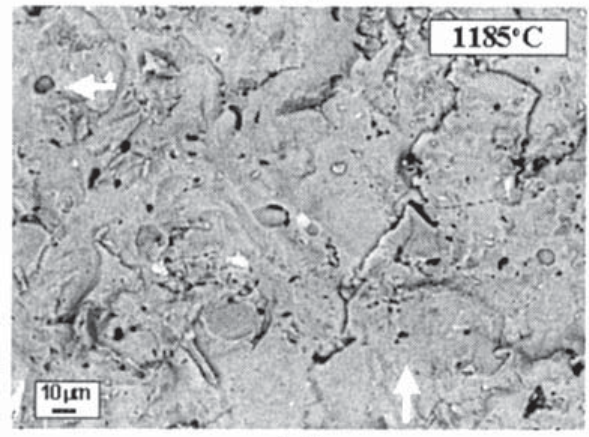

(d)

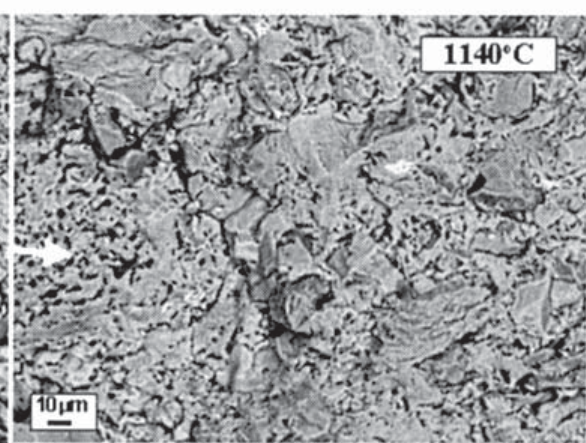

(b)

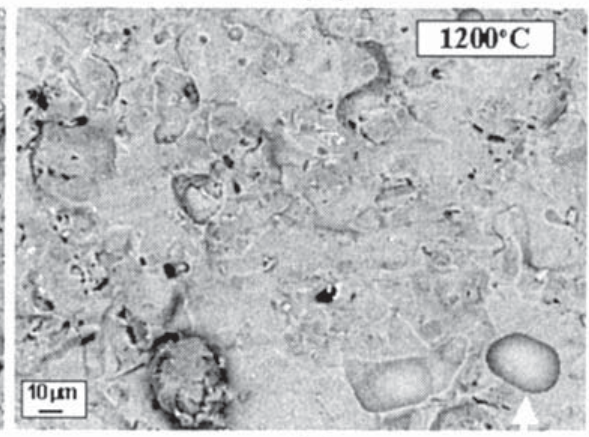

(e)

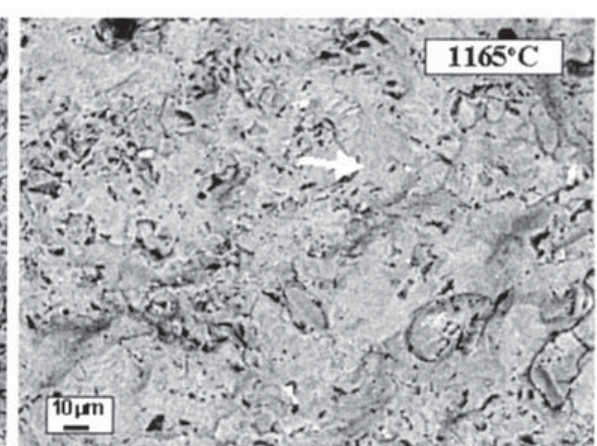

(c)

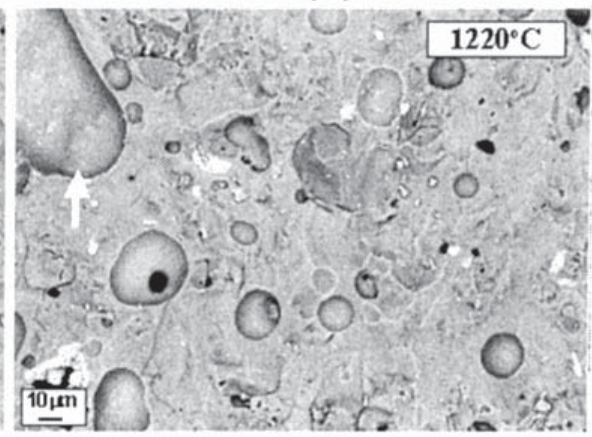

(f)

Figura 5: Micrografias de microestruturas da massa ilustrada na Fig. 4 por meio de Microscopia Eletrônica de Varredura ilustrando a evolução da microestrutura, nas temperaturas obtidas nas curvas de gresificação (ver Fig. 4b). a) $1115^{\circ} \mathrm{C}$, b) $1140{ }^{\circ} \mathrm{C}$, c) $1165{ }^{\circ} \mathrm{C}$, d) $1185{ }^{\circ} \mathrm{C}$, e) 1200 ${ }^{\circ} \mathrm{C}$, f) $1220^{\circ} \mathrm{C}$. As setas indicam os diferentes tipos de porosidade, mencionados no texto.

[Figure 5: Scanning Electron Microscopy images of microstructures of the ceramic mix mass of Fig. 4 obtained by depicting the microstructure evolution, in the same temperatures obtained in the vitrification curves (see Fig. $4 b$ ). a) $\left.\left.\left.1115{ }^{\circ} \mathrm{C}, b\right) 1140{ }^{\circ} \mathrm{C}, \mathrm{c}\right) 1165{ }^{\circ} \mathrm{C}, d\right) 1185{ }^{\circ} \mathrm{C}, e$ ) $\left.1200{ }^{\circ} \mathrm{C}, \mathrm{f}\right) 1220{ }^{\circ} \mathrm{C}$. The arrows indicate the different porosity types, mentioned in the text.]

Tabela III - Desenvolvimento de uma massa cerâmica tradicional.

[Table III - Development of a traditional ceramic whiteware.]

\begin{tabular}{lcc}
\hline Componentes & \multicolumn{2}{c}{ Massas (\%) } \\
\hline & $1 \mathrm{a}$ & $1 \mathrm{~b}$ \\
\cline { 2 - 3 } M1 & 100 & 40 \\
\hline M2 & - & 20 \\
\hline M3 & - & 20 \\
\hline
\end{tabular}

a) Argila plástica. Foi usada uma amostra de argila (M1) de qualidade industrial. Estas argilas foram estudadas por meio de análise térmica diferencial (ATD) e termogravimétrica (ATG), assim como sua distribuição granulométrica.

b) Material não-plástico. M2 é uma areia composta fundamentalmente pela combinação de grãos de quartzo proveniente de rejeitos da indústria de beneficiamento de caulim.

c) Fundentes. Foram utilizados dois diferentes tipos de fundentes. A amostra M3 é um feldspato sódico-potássico, enquanto que a amostra M4 é uma matéria-prima rica em wolastonita.

As matérias-primas não-convencionais, de origem espanhola, são de três tipos:

a) Material não-plástico misturado com argilas plásticas.
M5 é uma rocha sedimentária formada por uma mistura de quartzo e ilita.

b) Material fundente misturado com argilas plásticas. M6 é uma riolita parcialmente alterada por fluidos ricos em magnésio, ocorrendo a transformação de parte dos feldspatos originais em argilominerais tipo ilita. M7 é um feldspato sódico que inclui filossilicatos tipo ilita-sericita, proveniente de um granito albitizado. M8 é uma argila formada por ilita, caulinita e montmorilonita em uma proporção que lhe dá excelentes propriedades de plasticidade, refratariedade e fundência.

c) Caulinita misturada com material fundente. M9 é uma rocha parcialmente caulinitizada, na qual ocorrem os minerais típicos dos granitóides, quartzo e feldspatos, com importantes proporções de caulinita e ilita.

De acordo com as características individuais de cada uma destas matérias-primas, foram desenvolvidas três séries de massas cerâmicas:

1) Massa cerâmica tradicional (ver Tabela III);

2) Massa cerâmica tradicional, com aditivos (ver Tabela IV);

3) Massa cerâmica não-tradicional (ver Tabela V).

Todas as composições de massas foram homogeneizadas mediante moagem por via úmida em um moinho rápido de laboratório. As barbotinas foram secas e peneiradas em uma peneira de $100 \mu \mathrm{m}$. Os corpos de prova cerâmicos foram conformados por prensagem em forma de pastilhas de $50 \mathrm{~mm}$ de diâmetro, utilizando uma prensa semi-automática de laboratório a pressões compreendidas na faixa $350-400 \mathrm{kgf} / \mathrm{cm}^{2}$. 
A queima foi realizada em um forno elétrico com uma curva de queima que simula o processo de queima industrial. As temperaturas máximas de queima para elaboração dos diagramas de gresificação foram compreendidas entre 1100 e $1240{ }^{\circ} \mathrm{C}$, com tempos de patamar de 5 minutos.

Uma vez preparados os corpos de prova cerâmicos, suas mineralogia e microestruturas foram estudadas por MEV. Por sua vez, os diagramas de gresificação foram elaborados a partir dos dados de retração linear e absorção de água.

\section{RESULTADOS}

\section{Massa tradicional}

As massas cerâmicas são tradicionalmente compostas por uma argila plástica, um material não-plástico à base de quartzo e um fundente à base de feldspatos, como indica a formulação apresentada na Tabela III. Na Fig. 4 são comparados os diagramas de gresificação da argila plástica M1 com o da massa de grés porcelânico resultante quando se incorporam os aditivos tradicionais, isto é, $20 \%$ em peso de material não-plástico de quartzo M2 e 40\% em peso do fundente feldspático M3 (ver as composições minerais na Tabela II). Esta composição de massa cerâmica apresenta uma formulação correta, pois se alcança um valor de absorção de água próximo a zero a temperaturas próximas a $1185^{\circ} \mathrm{C}$ para os quais também aparece o máximo da retração linear em torno de $8 \%$. Para temperaturas superiores, a retração linear diminui até valores ligeiramente superiores a $7 \%$ a $1220^{\circ} \mathrm{C}$.

Na Fig. 5 estão representadas as microestruturas formadas em cada uma das temperaturas do diagrama de gresificação, como elas são observadas por microscopia eletrônica de varredura. Este estudo permite observar como ocorre o processo de gresificação quando se adicionam materiais não-plásticos e fundentes.

A primeira observação foi realizada a $1115^{\circ} \mathrm{C}$ (Fig. 5a) ilustrando com clareza a matriz argilosa transformada [7] que apresenta porosidade aberta, assim como os grãos de quartzo e de feldspato (que se distinguem pelo contraste diferente, isto é, os de quartzo mais escuros e os de feldspato mais claros) relacionados à existência de porosidade interparticular. A seta central mostra uns grãos de quartzo e feldspato que entram em contato, enquanto a seta superior mostra um exemplo em que

Tabela IV - Desenvolvimento de uma massa cerâmica tradicional, com aditivos.

[Table IV - Development of a traditional ceramic whiteware, with additives.]

\begin{tabular}{lccc}
\hline \multirow{2}{*}{ Componentes } & \multicolumn{3}{c}{ Massas (\%) } \\
\cline { 2 - 4 } & $2 \mathrm{a}$ & $2 \mathrm{~b}$ & $2 \mathrm{c}$ \\
\hline M8 & 100 & 40 & 40 \\
\hline M3 & - & 40 & 40 \\
\hline M2 & - & 20 & 17 \\
\hline M4 & - & - & 3 \\
\hline
\end{tabular}

Tabela V - Desenvolvimento de massas cerâmicas nãotradicionais.

[Table V-Development of non-traditional ceramic whiteware.]

\begin{tabular}{lccccc}
\hline Componentes & \multicolumn{5}{c}{ Massas (\%) } \\
\cline { 2 - 6 } & $3 \mathrm{a}$ & $3 \mathrm{~b}$ & $3 \mathrm{c}$ & $3 \mathrm{~d}$ & $3 \mathrm{e}$ \\
\hline M8 & 33 & 26 & 23 & 20 & 16 \\
\hline M5 & 33 & 26 & 23 & 20 & 16 \\
\hline M9 & 33 & 26 & 23 & 20 & 16 \\
\hline M7 & - & 10 & 15 & 20 & 25 \\
\hline M6 & - & 10 & 15 & 20 & 25 \\
\hline Total de & - & & & & \\
fundentes & - & 20 & 30 & 40 & 50 \\
\hline
\end{tabular}

ambos os tipos de grãos estão separados. Freqüentemente, são usadas proporções de quartzo e feldspatos de acordo com a proporção do eutético nos diagramas de equilíbrio, com o objetivo de formar um fundido à mínima temperatura possível.

A $1140{ }^{\circ} \mathrm{C}$ (Fig. 5b), a porosidade aberta é relacionada ao componente argiloso, como no caso anterior, mas a porosidade interparticular relacionada ao componente feldspático tende a desaparecer (devido ao processo de fusão deste por reação com a matriz argilosa). Porém, a porosidade interparticular ligada aos grãos de quartzo (indicada pela seta) é muito marcante.

A microestrutura da massa a $1165^{\circ} \mathrm{C}$ (Fig. 5c) apresenta duas grandes diferenças com as anteriores. Em primeiro lugar é observada uma clara diminuição da porosidade aberta, relacionada com uma acentuada queda da curva de absorção de água no diagrama de gresificação. Em segundo lugar, a identificação dos limites entre os grãos de feldspato e a matriz argilosa torna-se mais difícil. Porém, os grãos de quartzo ainda são claramente distintos, e com eles, a porosidade interparticular, indicada pela seta.

A $1185{ }^{\circ} \mathrm{C}$ (Fig. 5d), a porosidade aberta aparece como pequenos poros arredondados que correspondem à porosidade residual fechada ligada à matriz de argilas e corresponde ao ponto do diagrama de gresificação em que se alcançam valores de absorção de água muito baixos. A esta mesma temperatura, de máximo de retração linear, distingue-se o primeiro aparecimento de porosidade fechada grossa em forma de poros arredondados, coincidindo com a fusão praticamente total dos feldspatos, que já não podem ser identificados por DRX nem observados por MEV.

Para esta temperatura e superiores, analisando-se por EDX (Espectroscopia de Dispersão de raios X), observa-se regiões com diferentes porosidades. Nas regiões onde aparece a porosidade residual fechada (seta inferior da Fig. 5d), são detectados altos conteúdos em $\mathrm{SiO}_{2}$ e $\mathrm{Al}_{2} \mathrm{O}_{3}$ e baixos conteúdos em álcalis, isto é, trata-se de áreas que correspondem à matriz argilosa transformada pelo incremento da temperatura com o fechamento da porosidade aberta devido à formação de um fundido ligado à fração ilítica rica em $\mathrm{K}_{2} \mathrm{O}$ do componente argiloso. Ao contrário, quando analisa-se pontualmente as 

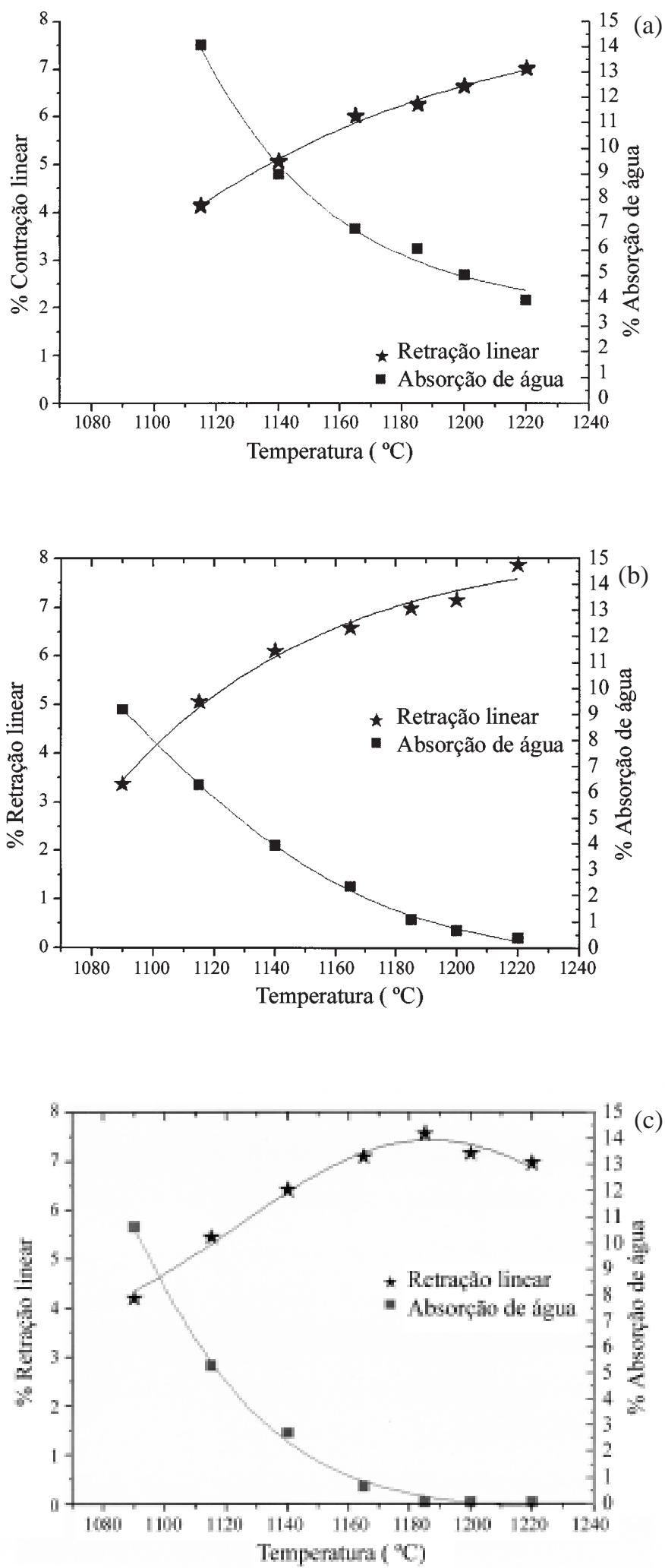

Figura 6: Composições de massa, com aditivo. a) Argila M8, b) $40 \% \mathrm{M} 8+40 \% \mathrm{M} 3+20 \% \mathrm{M} 2$. c) $40 \% \mathrm{M} 8+40 \% \mathrm{M} 3+17 \% \mathrm{M} 2+$ $3 \% \mathrm{M} 4$. As análises químicas e mineralógicas das matérias-primas M8, M3, M2 e M4 encontram-se na Tabelas I e II.

[Figure 6: Ceramic mixes, with addictive. a) clay M8, b) 40\%M8 + $40 \% M 3+20 \% M 2$, c) $40 \% M 8+40 \% M 3+17 \% M 2+3 \% M 4$. The chemical and mineralogical analyses of the M8, M3, M2 and M4 raw materials are in Tables I and II.] regiões onde a porosidade fechada grossa é desenvolvida (seta superior esquerda na Fig. 5d), ilustram-se composições químicas semelhantes às iniciais dos fundentes feldespáticos. Consequentemente, o início da formação da porosidade fechada grossa está relacionado de forma direta à fusão dos grãos de feldspatos.

Quando as peças são aquecidas a $1200^{\circ} \mathrm{C}$, observa-se uma marcante diminuição na porosidade residual fechada, mas aparece claramente desenvolvida a porosidade fechada grossa (seta na Fig. 5e), mas até mesmo depois do tratamento a estas temperaturas, a porosidade interparticular ainda aparece relacionada aos grãos de quartzo.

A $1220^{\circ} \mathrm{C}$, observa-se um aumento na proporção de poros fechados e um incremento no tamanho destes, chegando a intercomunicar-se (seta na Fig. 5f) substituindo por uma porosidade grossa aberta que é a responsável pelo aumento da absorção de água nos diagramas de gresificação.

Como conclusão, foi demonstrada claramente a existência de três porosidades, com origens e evoluções totalmente diferentes, cada uma delas associada a um dos componentes da massa:

i) A porosidade aberta é relacionada à fração argilosa do componente plástico da massa (Fig. 5a). Esta se deve à redução do volume inicial devido à perda de massa, e de certa maneira, pelos processos de desidratação a baixa temperatura, mas principalmente pela desidroxilação e pela transformação em mulita, estrutura cuja densidade é maior que a das argilas transformadas.

ii) A porosidade fechada é gerada pelo componente fundente da massa, e principalmente aparece associada aos grãos de maior tamanho (Fig. 5b). Esta relação foi proposta previamente. Além disso, do ponto de vista prático é sabido que há uma correlação direta entre a porosidade fechada (que sai à superfície nos processos de polimento superficial), a resistência às manchas e a granulometria dos feldspatos fundentes. Porém, não há uma explicação das causas deste efeito.

iii) A porosidade interparticular é ligada aos contatos dos grãos de quartzo do componente não-plástico (mas também aos grãos de feldspato quando não ocorre sua reação por fusão com a matriz argilosa). Seu aparecimento deve ser durante o resfriamento, devido aos valores muito diferentes dos coeficientes de dilatação térmica. Em outras palavras, durante o resfriamento, os grãos de quartzo contraem mais que o resto da massa, ficando suas interfaces bem separadas e dando lugar à porosidade interparticular a temperatura ambiente (Fig. $5 \mathrm{c}$ ).

Por outro lado, pode-se dizer que a adição de quartzo e feldspatos como grãos discretos, empregando matérias-primas refinadas, com homogeneidade mineralógica, não é a melhor opção para produzir fundidos de baixa temperatura relacionados com os eutéticos dos diagramas de fase correspondentes. Consequentemente, seria necessário pensar que a adição de grãos mistos (formados por mais de uma fase mineral com uma ou mais superfícies de contato) às argilas plásticas poderia ser vantajoso sob o ponto de vista da gresificação das massas. Este aspecto será explorado a seguir.

Finalmente, por meio de otimização do componente fundente seria possível obter massas nas quais a porosidade aberta diminuísse a valores pequenos a menores temperaturas. 
(a)

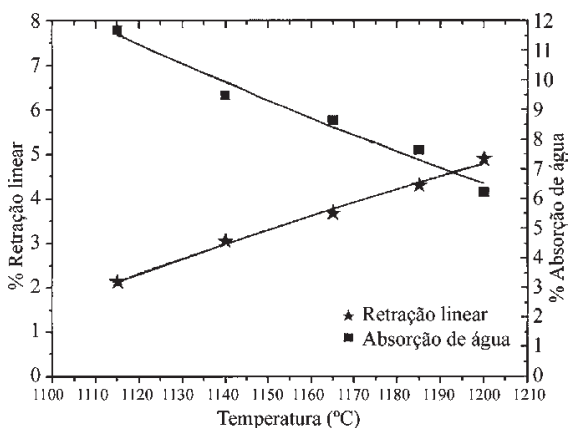

(d)

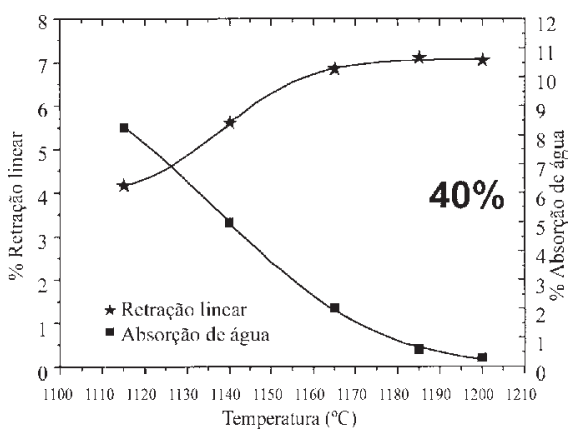

$(\mathrm{g})$

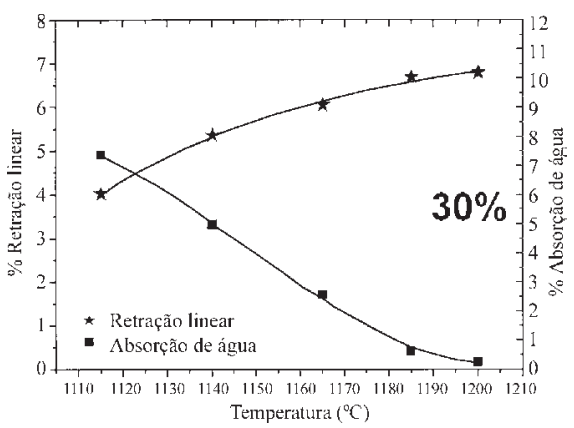

(b)

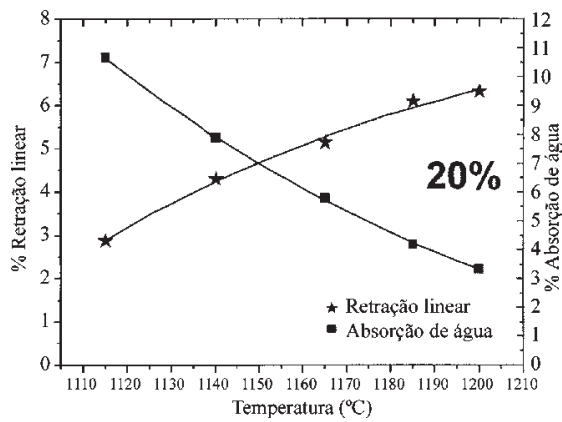

(e)

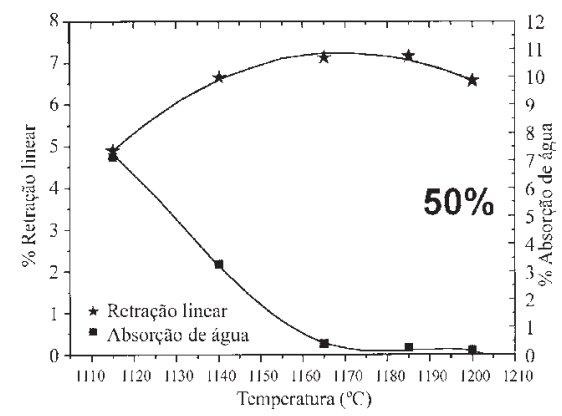

(h)

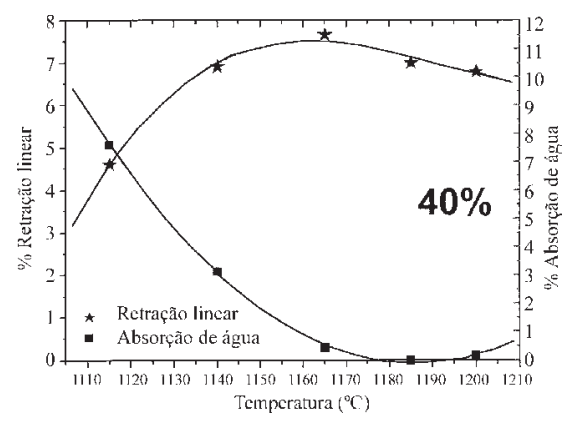

(c)

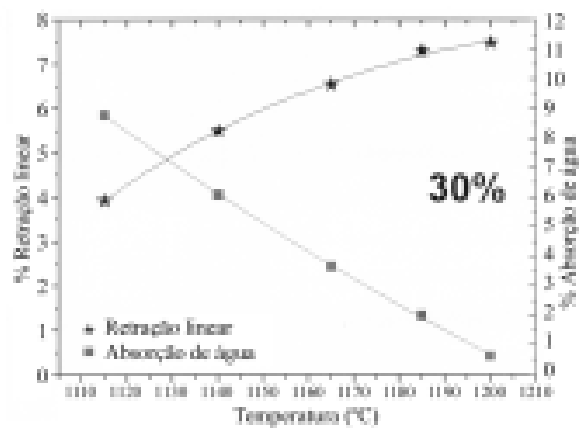

(f)

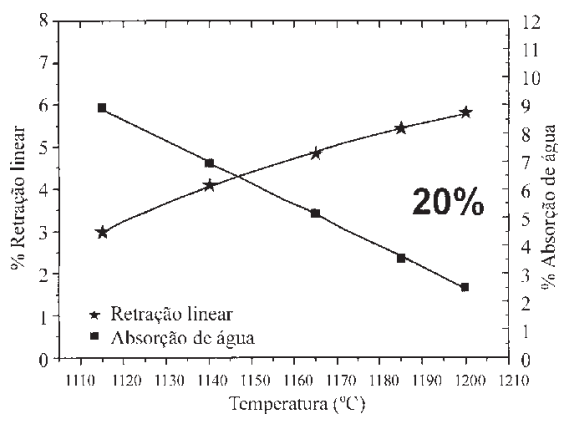

(i)

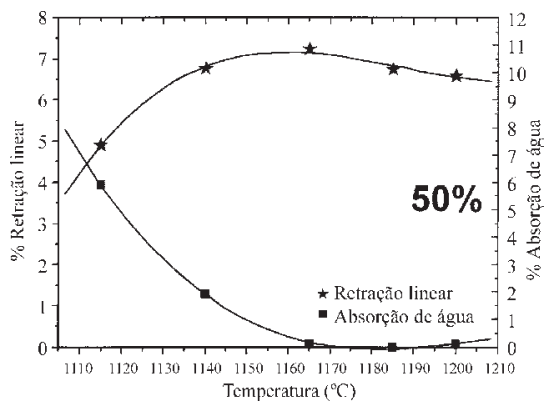

Figura 7: Curvas de gresificação de composições de massas não-tradicionais, conforme indica a Tabela III. a) massa 3a. b) massa 3b. c) massa 3c. d) massa 3d. e) massa 3e. f) massa 3b otimizada. g) massa 3c, a mais otimizada, em destaque. h) massa 3d otimizada. i) massa 3e otimizada. Em cada uma das curvas está indicada a quantidade total de fundentes de cada massa, conforme indica a Tabela V.

[Figure 7: Vitrification curves of non-traditional ceramic mixes, as indicated in Table III. a) mix 3a, b) mix 3b, c) mix 3c, d) mix 3d, e) mix $3 e, f)$ optimized mix $3 b, g$ ) more optimized mix $3 c$, outstanding, (h) optimized mix $3 d$, (i) optimized mix $3 e$. In each curves the total content of fluxes for each mix is indicated, according to Table V.]

Neste sentido, seria necessário introduzir algum material que reagisse com o componente argiloso em maior extensão que os grãos de feldspatos. Para isto, na bibliografia disponível utilizou-se filosilicatos laminares com lâminas entre as partículas da argila plástica, como o talco e os silicatos fibroso (por exemplo, wolastonita) que podem apresentar tamanhos de partícula pequenos.

\section{Massas tradicionais com aditivos}

Com o objetivo de explorar o efeito da adição de wolastonita às massas tradicionais formadas pelos componentes plástico, não-plástico e fundente, foi usada uma argila plástica com altas porcentagens de caulinita. Os caulins são adicionados às massas de grés porcelânico não só para proporcionar brancura mas também, devido a seu caráter refratário, contribuir para a estabilidade dimensional. Fica claro que um efeito colateral de tal adição é a dificuldade na obtenção de valores baixos de absorção de água nas temperaturas normais de queima (aproximadamente $1200{ }^{\circ} \mathrm{C}$ ). Porém, a argila M8 (ver Tabelas I e II) contém grãos de caulinita de pequeno tamanho devido a beneficiamentos que resultam muito interessantes para obter as duas características mencionadas, isto é, brancura e estabilidade dimensional. Por outro lado, como ocorre com a argila M1, a presença de caulinita não significa que a refratariedade aparecerá, já que a variável forte é o tamanho de partícula. Também os conteúdos em ilita e principalmente montmorilonita também contribuem para a fundência.

A Fig. 6 apresenta o desenvolvimento de uma massa cerâmica (ver Tabela IV) baseada na argila M8 que além de caulinita, apresenta montmorilonita e sericita (massa 2a). A Fig. 6a apresenta o diagrama de gresificação desta amostra, sendo obtidos 
os valores de 4\% de absorção de água e de 7\% de retração linear a $1220{ }^{\circ} \mathrm{C}$. Quando se formula uma massa tradicional (2b) com $40 \%$ de componente fundente (M3) e $20 \%$ de material nãoplástico a base de quartzo (M2), obtém-se um diagrama de gresificação com porosidade aberta nula a $1220^{\circ} \mathrm{C}$ (Fig. 6b). O diagrama de gresificação ilustrado na Fig. $6 \mathrm{c}$ apresenta esta massa (2c) com uma substituição de 3\% do componente não-plástico M2 por uma matéria-prima rica em wolastonita (M4). O resultado é que os valores de porosidade típicos do grés porcelánico são alcançados a aproximadamente $1170{ }^{\circ} \mathrm{C}$ [8], e com estabilidade dimensional suficiente para os processos produtivos deste material, além de uma retração linear em torno de 7,5\%, compatível com o processo de esmaltação do mesmo.

\section{Massas não-tradicionais}

Como apresentado anteriormente, quando matérias-primas formadas por minerais em grãos individuais são introduzidas nas massas, ocorre uma sensível ausência de contatos entre estes. Por este motivo, foi estudado o uso de matérias-primas não-tradicionais na indústria cerâmica, isto é, materiais que não têm uma função de componente específico, mas que são misturas de minerais com funções específicas. O termo materiais geológicos especiais foi utilizado para referenciar a rochas formadas seja por material não-plástico mais argila plástica $\mathrm{NP}+\mathrm{AP}$ (M5), por fundente mais argila plástica (M6, M7), refratário (caulim) mais fundente C+F (M9). Na Tabela V são ilustradas as proporções das matérias-primas nas massas correspondentes aos diagramas de gresificação da Fig. 7.

A massa " $3 a$ " corresponde a uma mistura de materiais que contêm argilas e que, seguindo a mesma metodologia dos desenvolvimentos anteriores, supõe a situação de partida a partir da qual se tenta conduzir as curvas a mínima porosidade e máxima retração linear por meio de aditivos fundentes. A Fig. 7 a mostra que a $1200{ }^{\circ} \mathrm{C}$ a absorção de água é superior a $6 \%$ nesta mistura. Observa-se que a situação de partida na mistura "3a" é muito mais refratária que a das massas tradicionais (Fig. 4a) e das com aditivos (Fig. 6a).

A partir da massa "3a" foram realizados duas séries de massas com conteúdos crescentes na proporção de matériasprimas que contêm fundentes. $\mathrm{Na}$ série "b-c-d-e" correspondentes às massas $3 \mathrm{~b}, 3 \mathrm{c}, 3 \mathrm{~d}$ e $3 \mathrm{e}$, os fundentes foram adicionados em proporções crescentes, como recebidos, enquanto que na série "f-g-h-i" correspondentes às massas $3 b$, $3 \mathrm{c}, 3 \mathrm{~d}$ e $3 \mathrm{e}$, os fundentes foram adicionados nas mesmas proporções, porém, passados em peneira $100 \mu \mathrm{m}$.

$\mathrm{Na}$ primeira série, devido às partículas grosseiras das massas, as observações por MEV das microestruturas destes materiais cerâmicos, nas diferentes temperaturas permitiram determinar um desenvolvimento bimodal da porosidade. Desta forma foi confirmado que a de tipo aberto ocorre nas partículas de argila e a de tipo fechado (com grande extensão nestes casos) aparece nas partículas de feldspatos. Nas massas " $3 \mathrm{~d}$ " e "3e", a estabilidade dimensional é alcançada a temperaturas muito menores do que o fechamento da porosidade aberta. De qualquer maneira, estas massas poderiam ser de interesse para suportes de grés porcelânico esmaltado, com matérias-primas de custos muito baixos.
Na segunda série, o efeito fundente das adições de matériasprimas que contêm feldspatos é aumentado, com relação à série anterior. Por exemplo, com adições de 30\% de M6+M7 na massa " 3 c" a $1185^{\circ} \mathrm{C}$ são obtidos valores superiores a $3 \%$ de absorção de água, enquanto que a massa "3c otimizada" está em torno de $0,5 \%$. Adições superiores têm um marcante efeito fundente, pois a massa " 3 e otimizada" apresenta as características de porosidade aberta do grés porcelânico a temperaturas inferiores a $1165^{\circ} \mathrm{C}$, embora apresentem uma estreita margem de estabilidade dimensional.

\section{CONCLUSÕES}

A queima de massas cerâmicas para suportes de grés é realizada em fornos que podem alcançar até uns $1175^{\circ} \mathrm{C}$. No grés porcelânico a queima é feita a uns $1200^{\circ} \mathrm{C}$. Esta diferença se traduz em produção com fornos diferentes, isto é, o interesse na produção de grés porcelânico demanda a aquisição de maquinaria nova. A conseqüência principal deste estudo é que pode-se fabricar suportes de revestimentos cerâmicos de grés porcelânico com os fornos convencionais de grés, não sendo necessário os investimentos em maquinaria, e sim em pesquisa de novas matérias-primas. Este trabalho apresenta evidências da possibilidade de produção de grés porcelânico em fornos convencionais de queima de grés graças ao uso de formulações de massas modificadas.

É provado que o uso de materiais geológicos especiais para massas cerâmicas, com ocorrência principalmente de grãos mistos, não só pode ser interessante do ponto de vista econômico, mas também energético e estratégico, pois permite produzir suportes de grés porcelânico esmaltado, no mínimo.

\section{REFERÊNCIAS}

[1] W. M. Carty, U. Senapati, Porcelain - Raw materials, processing, phase evolution and mechanical behavior, J. Am. Ceram. Soc. 81, 1 (1998) 3-20.

[2] V. T. L. Bogahawatta, A. B. Poole, Estimation of optimum firing conditions for kaolinitic clay bodies, Br. Ceram. Trans. J. 90 (1991) 52-56.

[3] Sacmi Research Center, Pavimento - Floor tiles, documento PDF extraído de www.sacmi.com, 2002.

[4] L. Lucarelli, V. Venturi, The mercury porosimeter: Use in structural investigations of porcelain stoneware tile, Industrial Ceramics 17, 2 (1997) 74-77.

[5] M. J. Orts et. al., Porcelain tile behaviour during polishing, Bol. Soc. Esp. Cer. Vidr. 40, 6 (2001) 447-455.

[6] Sacmi Research Center, Gres fine porcellanato - Fine porcelainized stoneware, documento PDF extraído de www.sacmi.com, 2002.

[7] G. W. Brindley et. al., High-temperature reactions of clay mineral mixtures and their ceramic properties: III, Shrinkage and porosity in relation to initial mineralogy, J. Am. Ceram. Soc. 44, 1 (1961) 42-47.

[8] L. Sanchez-Munoz et. al., Elaboration of porcelain stoneware tiles at 1170 degrees $\mathrm{C}$ by addition of wollastonite, Euro Ceramics VII 1-3, 206-2 (2002) 2205-2208.

(Rec. 15/04/02, Ac. 26/07/02) 